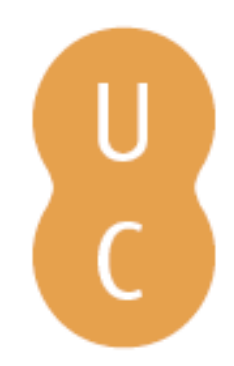

\title{
pommalina
}

\section{Quintino Bocaiúva e o sentimento antiportuguês na gênese da República Brasileira}

Autor(es): $\quad$ Mendes, José Sacchetta Ramos

Publicado por: Imprensa da Universidade de Coimbra

URL

persistente:

URI:http://hdl.handle.net/10316.2/31147

DOI:

DOI:http://dx.doi.org/10.14195/978-989-26-0497-8_15

Accessed : $\quad$ 26-Apr-2023 03:10:05

A navegação consulta e descarregamento dos títulos inseridos nas Bibliotecas Digitais UC Digitalis, UC Pombalina e UC Impactum, pressupõem a aceitação plena e sem reservas dos Termos e Condições de Uso destas Bibliotecas Digitais, disponíveis em https://digitalis.uc.pt/pt-pt/termos.

Conforme exposto nos referidos Termos e Condições de Uso, o descarregamento de títulos de acesso restrito requer uma licença válida de autorização devendo o utilizador aceder ao(s) documento(s) a partir de um endereço de IP da instituição detentora da supramencionada licença.

Ao utilizador é apenas permitido o descarregamento para uso pessoal, pelo que o emprego do(s) título(s) descarregado(s) para outro fim, designadamente comercial, carece de autorização do respetivo autor ou editor da obra.

Na medida em que todas as obras da UC Digitalis se encontram protegidas pelo Código do Direito de Autor e Direitos Conexos e demais legislação aplicável, toda a cópia, parcial ou total, deste documento, nos casos em que é legalmente admitida, deverá conter ou fazer-se acompanhar por este aviso. 
Armando Malheiro da Silva

Maria Luiza Tucci Carneiro

Stefano Salmi

Coordenação

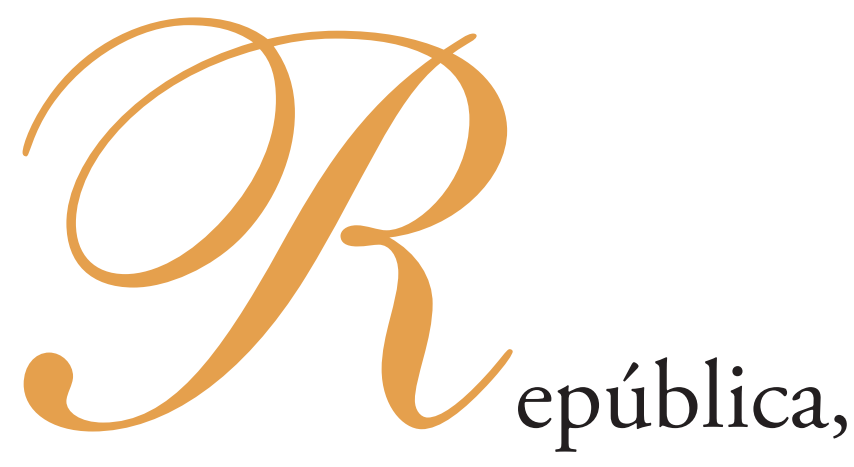

Republicanismo

e Republicanos

Brasil • Portugal • Itália 
José Sacchetta Ramos Mendes

\section{QUINTINO BOCAIÚVA E O SENTIMENTO ANTIPORTUGUÊS NA GÊNESE DA REPÚBLICA BRASILEIRA}

O período imediato que seguiu à Proclamação da República no Brasil foi marcado pela intolerância aos imigrantes portugueses, a despeito do decreto imposto pelo Governo Provisório, em Dezembro de 1889, que naturalizou coletivamente os estrangeiros residentes no País, outorgando-lhes a cidadania ${ }^{527}$. Desde o lançamento do Manifesto Republicano, duas décadas antes, os adversários de Dom Pedro II buscavam identificar Portugal e seus súditos com a Monarquia. "Somos da América e queremos ser americanos"528, dizia a carta de 1870, fundadora do movimento pela República, a fazer uso de um anacrônico mote anti-colonial para investir contra o Império.

No mesmo sentido, após a instauração do novo regime, propostas de reabilitar a forma monárquica passaram a ser qualificadas de estrangeirismo lusófilo, "cujas raízes se prendem ao solo da Europa e às suas Constituições políticas”, 29 ,

\footnotetext{
${ }^{527} \mathrm{O}$ presente ensaio foi elaborado no âmbito da pesquisa para a tese de doutoramento intitulada Laços de Sangue. Privilégios e intolerância à imigração portuguesa no Brasil (1822-1945), defendida pelo autor no Depto. de História da Faculdade de Filosofia, Letras e Ciências Humanas da Universidade de São Paulo (FFLCH/USP), em Abril de 2007, sob orientação da Prof. Dra. Maria Luiza Tucci Carneiro. A documentação que fundamenta a pesquisa foi consultada no Arquivo Histórico do Itamarati, Rio de Janeiro, e no Arquivo Histórico-Diplomático do Ministério dos Negócios Estrangeiros de Portugal, em Lisboa.

528 "Manifesto Republicano", editado originalmente no jornal A República. Rio de Janeiro, 03.11.1870; transcrito na Revista de História. São Paulo: FFLCH/USP, n. 84.

${ }^{529}$ BOCAIÚVA, Quintino - "Pela República", editorial do jornal O Paiz. Rio de Janeiro, 18.12.1889; anexo ao ofício confidencial n. 21 do Conde de Paço d'Arcos, encarregado de negócios de Portugal no
} 
no dizer do Ministro das Relações Exteriores do primeiro governo republicano, Quintino Antônio Ferreira de Sousa (1836-1912), que adotara o nome indígena Bocaiúva para afirmar seu nativismo.

Quintino Bocaiúva foi um dos raros civis a participar pessoalmente da ação militar que, em 15 de Novembro de 1889, depôs a família Bragança de seu reinado sul-americano, tornando-se um símbolo do poder popular da República, o novo eixo político que deveria substituir o pólo antes representado pela figura do imperador. É nesta condição que foi alçado ao comando da chancelaria do Rio de Janeiro, responsável pelo convencimento internacional da novíssima situação. Jornalista de profissão e ativista republicano de longa data, Bocaiúva enxergava os meandros da política externa por um viés distinto daquele que tradicionalmente compunha a diplomacia brasileira com os países da Europa.

No que tange ao relacionamento entre o Brasil e Portugal, divergências até então tratadas pela via de mornas negociações, quase sempre por meio de uma linguagem evocativa de fraternidade entre as duas Nações, na primeira fase da República viraram motivo de rusgas sérias, cujo agravamento e evolução levariam à ruptura alguns anos mais tarde. Com efeito, a difícil relação do Estado republicano brasileiro, em sua fase inaugural, com Portugal monárquico atingiu o ponto crítico em 1894/1895, quando se deu o rompimento diplomático oficial, o único na história das relações luso-brasileiras.

Já nos meses posteriores à Proclamação da República, na Capital Federal e em outros centros urbanos, imigrantes portugueses tornaram-se suspeitos de favorecer a restauração do Império. A desconfiança era reforçada pelas notícias do exílio da família de Dom Pedro II na Corte lisboeta de seu sobrinho-neto, o rei Dom Carlos I. O falecimento do ex-monarca brasileiro na Europa, em 5 de Dezembro de 1891, reacendeu velhos antagonismos. Manifestações antiportuguesas tornaram-se mais freqüentes. A correspondência de diplomatas lusos dava mostras dos ataques sofridos na época por seus conterrâneos no Brasil.

Chamou atenção, em particular, o encadeamento de hostilidades ocorrido no Rio de Janeiro nos dias seguintes à morte do imperador deposto: um comício em praça pública reunindo numerosa assistência contra os moradores portugueses

Brasil, ao Conde de Valbom, Ministro dos Negócios Estrangeiros de Portugal; Rio de Janeiro, 24.12.1891; Legação de Portugal no Rio de Janeiro (LPRJ), correspondência recebida, 1890/1891, caixa 223, maço 1, Arquivo Histórico-Diplomático (AHD) do Ministério dos Negócios Estrangeiros de Portugal. 
da cidade, a publicação na imprensa de virulentos textos editoriais antilusitanos e o envio de uma carta-ameaça, de forte caráter xenófobo e nacionalista, à legação diplomática de Portugal.

Tais gestos expressavam o recrudescimento da lusofobia - fenômeno vivenciado noutros momentos de crise política do século XIX brasileiro - e envolviam a figura de Quintino Bocaiúva como personagem de trânsito social na sede da República e homem próximo ao círculo do poder, ainda que em Dezembro de 1891 estivesse afastado do gabinete de governo. Bocaiúva renunciara ao Ministério das Relações Exteriores em Fevereiro daquele ano, quando a Constituição republicana entrou em vigor, passando a concentrar suas atividades no jornalismo, à frente do influente diário carioca O Paiz.

O Brasil adentrava, então, seu apogeu imigrantista, período iniciado nas últimas décadas do Império e que se prolongou até a virada do século xx. Em 1889, ano da Proclamação da República, entraram no país 65 mil imigrantes estrangeiros; em 1890, foram 106 mil e, em 1891, o número de adventícios aportados elevou-se a 215 mil pessoas. No decênio posterior à instituição da nova forma de governo (1890/1899), desembarcaram no Brasil mais de um milhão de imigrantes europeus, 75\% dos quais provindos da Itália e 15\% de Portugal ${ }^{530}$. Foi o ápice do movimento imigratório brasileiro, em todos os tempos.

A entrada maciça de italianos, por sua vez, trazia um elemento inédito para a demografia brasileira, marcada pela predominância da origem portuguesa na população branca do País. Os italianos, no entanto, dirigiam-se para as zonas agrícolas do interior, principalmente para São Paulo e Rio Grande do Sul, enquanto os portugueses continuavam a afluir, na maior parte, para as grandes cidades litorâneas, destacadamente para o Rio de Janeiro. A capital concentrava a maior coletividade portuguesa do País, disseminada num amplo corte social que perpassava todo o espectro urbano, da elite ao funcionalismo de classe média e aos empregados em funções subalternas, substitutos dos antigos escravos de ganho.

É nesse contexto que deve ser compreendido o antilusitanismo dos primeiros anos da República no Brasil. Desde o processo de emancipação frente a Portugal, o sentimento contra os portugueses havia produzido diferentes

\footnotetext{
${ }^{530}$ Instituto Brasileiro de Geografia e Estatística, Anuário estatístico. Séries históricas. Rio de Janeiro, 1951.
} 
hostilidades, sobretudo no Rio. No final do século XIX, porém, tais posturas já não se vinculavam a tensões pós-coloniais, e sim à presença de numerosa coletividade imigrada. Após a Proclamação da República, a onda de patriotismo que se irradiou a partir do novo eixo de poder contrapôs a idéia de povo brasileiro à noção de pátria estrangeira, na qual o imigrante português se encaixava como nenhum outro grupo.

\section{Um relato feito na véspera do Natal de 1891}

O encadeamento de manifestações hostis ocorridas em Dezembro de 1891 principiou com o ato público realizado no dia 16, no centro do Rio de Janeiro, reunindo uma pequena multidão que investia palavras de ordem contra Portugal e os portugueses. A correspondência diplomática da época expressou a indignação dos diplomatas lusos com o ataque a seus nacionais e ao seu País. Ressaltou também a aparente tolerância das autoridades. Um relato escrito na véspera do Natal daquele ano por Carlos Eugénio Correa da Silva, Conde de Paço d'Arcos, Ministro responsável pela Legação de Portugal na capital brasileira, dava conta de que o "meeting de praça pública contra os portugueses [aconteceu] com assistência da polícia que, impassível, ou conivente, deixou que em altos berros, e com ruidosas aclamações, os oradores vomitassem impropérios e injúrias à França e a Portugal”,531.

O relato do diplomata constava da comunicação confidencial dirigida ao Conde de Valbom, Ministro dos Negócios Estrangeiros de Lisboa. A difusão do ânimo contrário ao Reino de Portugal e a imigrantes portugueses radicados no Brasil era, do ponto de vista do Ministro Paço d'Arcos, estimulada a partir de círculos próximos aos poderes da República e trazia a marca do ex-chanceler Bocaiúva.

A opinião do diplomata luso era, em parte, motivada por um editorial redigido por Quintino Bocaiúva, publicado em O Paiz, no qual propalava que os inimigos da nova forma de governo apoiavam-se "não em elementos nacionais, que de todo lhes faltam, mas em elementos bastardos, que socialmente e

${ }^{531}$ Ofício confidencial n. ${ }^{\circ} 21$ do Conde de Paço d'Arcos ao Conde de Valbom; RJ, 24.12.1891; op. cit. 
etnologicamente são e sempre foram infensos à grandeza e à prosperidade e do Brasil livre e do Brasil americano" ${ }^{532}$. Publicado dois dias após o comício contra os portugueses, o artigo editorializado de Bocaiúva descreveu o ato público antilusitano como um incidente ruidoso que "interrompeu a calma habitual de nossa cidade", observando que nele "o que transparece é a vibração da alma nacional, irradiando-se no entusiasmo da mocidade" ${ }{ }_{33}$.

Ainda que Portugal e os portugueses não tenham sido expressamente mencionados no texto de jornal assinado por Bocaiúva, os comentários do ex-chanceler deixavam implícito que, na sua acepção, eram os monarquistas portugueses os inimigos históricos da República brasileira.

Conde de Paço d'Arcos comunicou às autoridades de Lisboa que, em protesto pela ocorrência da manifestação pública antiportuguesa, emitira uma nota oficial ao governo do Rio de Janeiro. Deixou claro, entretanto, que fora "prudentíssimo" no uso das palavras, para evitar melindres num período de crescente tensão, que vinha se agravando desde os meses anteriores. De fato, informações originárias nas representações consulares lusitanas de outras regiões brasileiras, enviadas à Legação de Portugal no Rio, deixavam antever uma atmosfera pouco amistosa aos imigrantes lusitanos noutras cidades, em particular nas capitais do Norte, como Belém, Recife e Salvador.

Um relatório elaborado pelo Consulado de Portugal em Pernambuco, ainda em Julho de 1890, notificava que apenas entre 15\% e 20\% dos imigrantes residentes naquela jurisdição haviam feito a opção de preferência pela cidadania portuguesa - alternativa jurídica à naturalização coletiva imposta pelo governo republicano em 1889, conforme previsão definida no próprio decreto que a instituiu. O motivo da pequena adesão à nacionalidade de origem, segundo o relatório consular, era o receio de agravamento das hostilidades de que eram vítimas os estrangeiros, notadamente os portugueses ${ }^{534}$.

O antilusitanismo verificado na Capital Federal em Dezembro de 1891 registrou outro episódio na mesma data da publicação do editorial de Quintino

\footnotetext{
${ }^{532}$ BOCAIÚVA, Quintino, op. cit.

533 Ibidem

534 Ofício reservado n. 74 de Antonio Joaquim Barboza Vianna, encarregado do Consulado de Portugal em Pernambuco, a Manuel Garcia da Rosa, da Legação de Portugal no Rio de Janeiro; Recife, 11.07.1890; LPRJ, correspondência recebida, 1890/1891, caixa 223, maço 1, AHD.
} 
Bocaiúva na imprensa. Naquele dia pela manhã, a Legação de Portugal recebeu uma violenta carta de repúdio, com ameaça de morte a seus cidadãos no Brasil. A justificar tamanha intransigência, o autor incógnito da mensagem alegava "a indigna ingratidão" da comunidade lusitana estabelecida no País, "que prosperou e enriqueceu à sombra das nossas leis" ${ }^{535}$. A carta não era apócrifa, entretanto, mas firmada por um desconhecido e incerto Grupo Vermelho - Sociedade Irredentista, que assim se expressou:

"Os portugueses pobres e desprotegidos abandonam a terra natal, onde a miséria ou a mediocridade os aguardava e, aportando neste país, cujo generoso povo não thes pergunta se são fidalgos ou plebeus, monarquistas ou republicanos, católicos ou livre pensadores, e são acolbidos indistintamente, ou melhor, com mais benevolência do que os outros estrangeiros, para depois abusarem tão cruelmente de nossa magnanimidade.

(...) portugueses de todas as condições fomentam às claras, ou ocultamente, o espírito de reação contra o governo constituído! Pois bem, querem a luta, tê-la-hão. Um grupo de brasileiros patriotas, indignados com estes fatos, deliberam responder a esta provocação organizando represálias que chegarão até o dinamite, ao punhal e ao incêndio às pessoas e bens dos súditos portugueses (...)

Morra a Nação portuguesa! Fora esta raça de judeus do Ocidente!"’36

A generalização intolerante contra os imigrantes portugueses e seu "espírito de reação contra o governo constituído" não levou em conta a diversidade entre eles, reconhecida, aliás, no trecho transcrito (fidalgos, plebeus, monarquistas, republicanos, católicos, livre pensadores). A carta-ameaça, sem tratar dessas diferenças, remetia seu grito de guerra e de morte a toda a "Nação portuguesa",

\footnotetext{
${ }^{535}$ Carta-ameaça à LPRJ; anexo n. ${ }^{\circ} 1$ ao ofício confidencial n. ${ }^{\circ} 21$ do Conde de Paço d'Arcos ao Conde de Valbom; RJ, 24.12.1891. Op. cit.

${ }^{536}$ Ibidem.
} 
nela definida como "raça de judeus do Ocidente", expressão herdada do anti-semitismo ibérico dos tempos coloniais ${ }^{537}$.

Alertado da existência de semelhanças entre o editorial de imprensa e os termos da carta-ameaça recebida pela Legação, o Conde de Paço d'Arcos comparou a grafia desta com um manuscrito do ex-Ministro brasileiro das Relações Exteriores. Depois, mais uma vez confidencialmente, notificou ao Governo de Lisboa:

"a letra se não é, parece-me a mesma! E além da minha própria observação, quatro pessoas idôneas (...) estão bem convencidas de que a anônima e a carta comparada são da mesma mão, que deverá, pois, ser aquela que escreveu o artigo." $" 538$

A suspeita do Conde de Paço d'Arcos contra Quintino Bocaiúva não foi levada a público. O diplomata português tampouco se queixou do incidente à chancelaria brasileira, possivelmente pelas implicações que enxergava, naquele instante em que a tensão republicano-monárquica resvalava para suposta oposição entre o nacional e o lusitano. Apesar dos registros do episódio na documentação diplomática de Portugal, não se conhece menção a ele na historiografia luso-brasileira. Em sua avaliação confidencial enviada à chancelaria de Lisboa, Paço d'Arcos opinou que a atuação de Bocaiúva, ainda que lhe parecesse "incrível, por vil e indigno - só [servia para] mostrar o rebaixamento a que chegou a cegueira política neste País, onde não se olham os meios de conseguir quaisquer fins que as facções desejam"s39.

Quanto ao Grupo Vermelho - Sociedade Irredentista, que subscreveu a carta, não se tem notícia de quem se tratava, nem de qualquer outra manifestação sua. Naquela única ocorrência conhecida, antiportuguesa e republicana, a denominação que assume afigura-se imprópria. O nome vem do movimento Italia irredenta, destacado na política européia do fim do século xIX por reclamar

\footnotetext{
${ }^{537}$ A analogia entre portugueses e judeus aponta para curiosa derivação do preconceito anti-semita ibérico, neste caso a investir genericamente contra a presença lusitana no Brasil; sobre a persistência do anti-semitismo no meio luso-brasileiro, ver CARNEIRO, Maria Luiza Tucci - Preconceito racial em Portugal e Brasil colônia. Os cristãos-novos e o mito da pureza de sangue. $3^{a}$ ed. São Paulo: Perspectiva, 2005.

${ }^{538}$ Ofício confidencial n. ${ }^{\circ} 21$ do Conde de Paço d'Arcos ao Conde de Valbom; RJ, 24.12.1891. op. cit.

539 Ibidem.
} 
territórios do Império Austro-Húngaro habitados por italianos étnicos, excluídos da Unificação Italiana consolidada nos anos 1870540. A impropriedade do termo, no contexto brasileiro, é ressaltada pela inclinação monárquica do irredentismo europeu, em oposição à República. A doutrina nacionalista do Rissorgimento, porta-voz de populações que alegadamente viviam sob jugo estrangeiro ${ }^{541}$, fica aqui reduzida a uma estreita conotação de xenofobia.

Centro Republicano Português, "desdouro" da coletividade lusa

Quintino Bocaiúva não desconhecia a adesão de muitos imigrantes portugueses ao republicanismo, desde os últimos anos do Império. O jornal O Paiz, que comandou como redator e editor, no qual escrevia seus libélos propagandísticos da República, pertencia ao Visconde de Matosinhos, figura notória na coletividade lusitana do Rio de Janeiro ${ }^{542}$. A simpatia de importantes personagens emigrados pela nova forma de governo do Brasil, inclusive gente com título de nobreza, chegou a causar preocupação em Lisboa. Nos anos seguintes à queda da Monarquia brasileira, o crescimento do Centro Republicano Português, com sede na Capital Federal, gerou intensa correspondência consular.

As difíceis relações de Portugal com o regime moviam-se em sentido inverso ao do ativismo em torno daquele $c l u b$ republicano, "desdouro da colônia portuguesa", nas palavras do Conde de Paço d'Arcos. "A maior parte dos membros são ex-portugueses, hoje brasileiros, e gente de outras Nações” ${ }^{43}$, informava o diplomata. Agrupamentos luso-republicanos semelhantes surgiram noutras cidades, entretanto, com fins comunitários e recreativos mais acentuados que o caráter político do congênere carioca ${ }^{544}$.

${ }^{540}$ VALLAUD, Dominique - Dictionnaire historique. Paris: Fayard, 1995, p. 484.

${ }^{541}$ MAYALL, James - Nationalism and international society. Cambridge: Mass Cambridge University Press, 1990, pp. 55-69.

542 CARVAlHO, José Murilo de - Os bestializados. São Paulo: Companhia das Letras, 1987.

${ }^{543}$ Ofício confidencial n. ${ }^{\circ} 22-A$ do Conde de Paço d'Arcos ao Conde de Valbom; Rio de Janeiro, 24.12.1891; LPRJ, correspondência recebida, 1890/1891, caixa 223, maço 1, AHD.

${ }^{544}$ Há notícias da fundação de grêmios republicanos da comunidade portuguesa, no período, em outras cinco cidades brasileiras: São Paulo, Santos, Belém do Pará, Recife e Pelotas (RS), além do Rio de Janeiro; sua localização em regiões diversas sugere a ampla aceitação do novo regime pelos imigrantes lusos no Brasil. 
Em Novembro de 1891, após a Revolta da Armada, que levou à renúncia do marechal Deodoro da Fonseca, as relações entre o Brasil republicano e Portugal monárquico se complicaram ${ }^{545}$. O almirante Custódio José de Melo, líder da sublevação, era amigo pessoal de Paço d'Arcos, principal representante do governo lusitano no País. A documentação diplomática guarda relatos do relacionamento amistoso entre ambos, amizade que tornava o diplomata português suspeito de envolvimento direto com as questões políticas internas brasileiras ${ }^{546}$.

A posse do vice-presidente Floriano Peixoto, também marechal, ainda em Novembro, em desacordo com a Constituição promulgada em Fevereiro - que previa a convocação de eleições em caso de vacância da Presidência da República nos primeiros dois anos do mandato, gerou novos movimentos militares, mais uma vez liderados por Custódio de Melo. Na seqüência da posse de Floriano, adiantando-se aos meios oficiais, o Centro Republicano Português do Rio de Janeiro declarou seu apoio:

“(...) aos correligionários brasileiros, na pessoa do ilustre e benemérito cidadão Floriano Peixoto, chefe supremo do governo que tão patrioticamente parece disposto a manter a ordem, a fazer respeitar a lei, e a regularizar e moralizar a administração, tirando aos inimigos das instituições democráticas todos os motivos de pretexto para infundadas agitações, condenáveis e funestos conluios, adversos à ordem e à prosperidade do Brasil”, ${ }^{\prime 47}$.

A reverência dos luso-republicanos aos correligionários brasileiros, motivo de aborrecimento dos círculos monárquicos dos dois países, reforçou a idéia de existência de uma suposta dualidade de posturas no interior da comunidade imigrante. Conforme essa visão dicotômica, que parece ter se renovado ao longo do século XIX, alguns portugueses estariam ao lado do Brasil, de suas

${ }^{545}$ NASCIMENTO, Álvaro - A ressaca da marujada: recrutamento e disciplina na Armada Imperial. $1^{\text {a }}$ ed. Rio de Janeiro: Arquivo Nacional, 2001.

${ }^{546}$ CERVO, Amado Luiz; MAGALHÃES, José Calvet de - Depois das caravelas. As relações entre Portugal e o Brasil 1808-2000. Instituto Camões. Lisboa: 2000, pp. 166-173.

${ }^{547}$ Ata da Assembléia Geral do Centro Republicano Português no Rio de Janeiro, de 20.12.1891; anexo ao ofício confidencial n. ${ }^{\circ} 22$ do Conde de Paço d'Arcos ao Conde de Valbom; RJ, 24.12.1891. do Conde de Paço d'Arcos ao Conde de Valbom; Rio de Janeiro, 24.12.1891; LPRJ, correspondência recebida, 1890/1891, caixa 223, maço 1, AHD. 
instituições e da nacionalidade; outros seriam inimigos históricos, e de longa data, da causa nacional, qual fosse a configuração da época: o movimento da Independência, a maioridade do imperador-menino nascido nesta pátria, a inauguração da República ou a posse do mais recente militar ocupante da Presidência.

A segunda Revolta da Armada, desta vez contra Floriano Peixoto, eclodiu entre Setembro de 1893 e Março de 1894, novamente com Custódio de Melo no comando dos rebeldes. Vencidos pelas forças leais ao presidente, os revoltosos pediram e obtiveram asilo político do governo português. Cerca de 500 militares brasileiros buscaram abrigo nas corvetas Mindelo e Afonso de Albuquerque, da Marinha lusitana, ancoradas na baía de Guanabara, sobrecarregando ao máximo as embarcações ${ }^{548}$.

O episódio foi compreendido por Floriano como uma afronta à soberania nacional e levou ao rompimento de relações com o governo de Portugal em Maio de 1894, situação que se manteve por dez meses, até Março de 1895, já sob a Presidência do civil Prudente José de Morais Barros (1894/1898). Aquele foi um dos momentos críticos no relacionamento luso-brasileiro. O desenlace diplomático anterior havia ocorrido de maneira informal e silenciosa, em 1831, na abdicação de Dom Pedro I, quando o reino português vivenciava um período de desorganização administrativa e sucessória, em decorrência da morte de Dom João VI.

O rompimento Brasil-Portugal dos primeiros anos da República deixava, porém, como conseqüência, a não-ratificação pelo Rio de Janeiro do Tratado de Comércio e Navegação, assinado pelos dois países em Janeiro de 1892, mas nunca remetido ao Congresso Nacional, que sequer o analisou. O acordo era uma antiga aspiração das autoridades lisboetas, que anteviam em seus co-nacionais emigrados um elemento facilitador da venda de produtos portugueses aos brasileiros, de quem, por sua vez, esperavam preferência comercial e isenções tributárias ${ }^{549}$.

\footnotetext{
${ }^{548}$ Sobre o rompimento Brasil-Portugal, ver COSTA, Sérgio Corrêa - A diplomacia do marechal: intervenção estrangeira na Revolta da Armada. $2^{a}$ ed. Brasília: EdUnB, 1979; ALVES, Francisco das Neves - "O rompimento diplomático brasileiro-lusitano ao final do século XIX, um estudo de caso". In LEITE, Renato Lopes (org.) - Cultura Epoder. Portugal e Brasil no século Xx. Curitiba: Juruá, 2003, pp. 89-104.

${ }^{549}$ Nota de Fernando Mattoso Santos, Ministro extraordinário de Portugal no Brasil, a Manoel
} 
As negociações para o tratado haviam sido iniciadas ainda durante o Império, tomaram forma sob o mandato de Deodoro da Fonseca (1889/1891) e foram concluídas no governo de Floriano Peixoto (1891/1894). A partir daí, a tramitação para a entrada em vigor do acordo emperrou, até ser definitivamente deixada de lado, com o asilo oferecido por Portugal aos revoltosos da Armada e a decorrente ruptura diplomática.

\section{Portugal e a legitimação da República brasileira}

O antilusitanismo brasileiro da primeira fase republicana, bem como o esfriamento das relações bilaterais entre Brasil e Portugal após a Proclamação da República, foram acompanhados por um paradoxo concomitante, tanto nos círculos intelectuais quanto políticos: a retomada do debate sobre a presença portuguesa nas bases de construção da nacionalidade. É certo que se tornou notório o exacerbamento do nativismo americanista no Brasil daquele período, assinalado, entre outros aspectos, nas temáticas da literatura e da música. Não obstante a inclinação nacionalista, anti-européia e em certos aspectos xenófoba, esta deve ser entendida como uma postura relativa e circunstancial, até mesmo pela razão de que, por outras vias, no esforço por se auto-legitimar, a República renovou o vínculo simbólico com Portugal.

Assim, o decreto que instituiu a bandeira nacional republicana - promulgado quando Quintino Bocaiúva era Ministro das Relações Exteriores e homem forte do gabinete da República - manteve a simbologia luso-brasileira e o concurso de elementos de origem portuguesa, como a orla azul com estrelas de prata e cores da antiga metrópole lusíada ${ }^{550}$. O verde mantido no pavilhão republicano do Brasil remete à Batalha de Aljubarrota, de 1385, quando os portugueses derrotaram os castelhanos.

Deodoro da Fonseca, Presidente da República do Brasil; RJ, 04.09.1891; Missões Estrangeiras no Brasil - Portugal/Grã-Bretanha, 1823/1922; estante 273, prateleira 1, maço 10, Arquivo Histórico do Itamarati (AHI).

${ }^{550}$ Decreto n. $^{\circ} 4$ de 19.11.1889. Decretos do Governo Provisório da República dos Estados Unidos do Brasil, 1889/1891. Rio de Janeiro: Imprensa Nacional, 1914, v. 1, pp. 3-4. 
Quando a bandeira definitiva da República brasileira foi instituída, em Novembro de 1889, substituindo a primeira versão, cujo desenho era uma cópia da bandeira listrada norte-americana, apenas com a mudança das cores vermelha e branca pelo verde e amarelo - o criador do novo projeto adotado, Raimundo Teixeira Mendes, traçou sua linhagem heráldica num texto de tons sentimentais publicado no Diário Oficial da União:

"Este símbolo [a bandeira nacional] lembra naturalmente a fase do Brasil-Colônia, nas cores azul e branca, que matizam a esfera, ao mesmo tempo que esta recorda o período do Brasil-Reino, por trazer a memória da esfera armilar.

Desperta a lembrança da fé gloriosa dos nossos antepassados, e ao descobrimento desta parte da América, não já por meio de um sinal que é atualmente um símbolo de divergência [a coroa], mas por meio de uma constelação [em cruz], cuja imagem só pode fomentar a mais vasta fraternidade. Porque nela o mais fervoroso católico contemplará os insondáveis mistérios da crença medieval, e o pensador mais livre recordará o caráter subjetivo dessa mesma crença e a poética imaginação de nossos avós"s51.

Permanências materializavam-se, daquele modo, na representação figurativa do novo regime, nada menos do que a "fomentar a mais vasta fraternidade" entre os povos do Brasil e de Portugal, nas palavras de Teixeira Mendes. Para além do discurso aparentemente contraditório com o estado de espírito patriótico, e no auge da dissonância republicano-monarquista, a evocação dos "antepassados" e a lembrança de "nossos avós" reabilitavam a idéia de existência um laço familiar lusíada entre Nações.

Num outro episódio, ocorrido em Janeiro de 1895, durante o rompimento diplomático luso-brasileiro, forças navais da Grã-Bretanha ocuparam a ilha Trindade, situada no Atlântico Sul, em frente ao litoral do Estado do Espírito Santo, historicamente pertencente ao Brasil. Ao tomar conhecimento da ocupação, o Governo do Rio de Janeiro protestou. Londres respondeu que Trindade

${ }^{551}$ MENDES, Raimundo Teixeira - "A Bandeira Nacional”. In Diário Oficial da União. Rio de Janeiro, 24.11.1889, p. 1. 
tinha sido abandonada, tornando-se res nullius para o direito internacional ${ }^{552}$. Os britânicos pretendiam usar a ilha para amarração de cabos telegráficos submarinos, e como ponto de apoio para suas embarcações na rota do extremo Sul do continente americano. Estavam dispostos a instaurar o litígio e chamavam por um arbitramento, a que o Brasil não admitia, considerando incontestáveis os seus direitos sobre aquele território insular.

Apesar das difíceis relações bilaterais, só reatadas em Março daquele ano, a imprensa portuguesa levantou-se contra a ocupação e deu visibilidade ao fato. Portugal, de sua parte, ofereceu ao Brasil os bons ofícios diplomáticos para ajudar na resolução do caso. Como Estado neutro, expôs documentalmente as razões histórico-jurídicas que faziam de Trindade uma ilha brasileira. Foram apresentados documentos do Arquivo Nacional da Torre do Tombo, de Lisboa, datados a partir de 1539, com ênfase para mapas, diários de viagem, expedições, salvamentos e outros comprovantes do exercício da jurisdição brasileira entre 1831 e 1893. A demonstração levou a Grã-Bretanha reconhecer, em Agosto de 1896, a soberania do Brasil sobre a ilha.

O reconhecimento gerou um movimento favorável ao então Presidente da República, Prudente de Morais. No Congresso Nacional, a moção de cariz patriótico que felicitou o governo pelo sucesso da negociação diplomática omitiu o papel de Portugal na resolução do conflito. Um grupo de parlamentares denunciou a omissão, destacadamente o deputado federal paulista Francisco Glicério de Cerqueira Leite, num discurso em que ressaltou o emprego pela diplomacia lusa da autoridade de quem conhecia e podia demonstrar a extensão de seus ex-domínios.

Juntamente com Quintino Bocaiúva, Francisco Glicério havia participado intensamente da campanha republicana da década anterior e integrou o primeiro governo da República, como Ministro da Agricultura. Pouco antes da deposição do imperador, Francisco Glicério chegou a propor a realização de um plebiscito popular para definir a continuidade ou o fim da Monarquia.

É interessante que, tendo feito parte do núcleo de poder inaugural da República, Francisco Glicério tenha se levantado em defesa da devida menção

\footnotetext{
552 GARCIA, Eugênio Vargas - Cronologia das relações internacionais do Brasil. Brasília: Fundação Alexandre de Gusmão e Alfa Omega, 2000, pp. 80-81.
} 
ao papel de Portugal nas negociações com Londres acerca da soberania brasileira sobre Trindade. Ainda mais pelo fato do ex-chanceler Bocaiúva ter assistido àquele debate no Congresso Nacional como senador, aparentemente sem se manifestar — após um curto período de atuação exclusiva no jornalismo, Quintino Bocaiúva retornara à política, tendo sido eleito senador pelo Rio de Janeiro, cargo em que permaneceu de 1892 a 1900.

Em Novembro de 1893, o governo de Portugal retirou o Conde de Paço d'Arcos da Legação no Rio de Janeiro, enviando para o posto o Conde de Paraty, melhor relacionado aos republicanos, tanto brasileiros quanto luso-emigrados. Era uma tentativa de normalizar os laços com a nova realidade política vivenciada apelo Brasil. No entanto, a lusofobia observada nos primeiros tempos da República ganharia novas formas. Os episódios de Dezembro de 1891 ficariam guardados na memória dos moradores do Rio. Por algum tempo, opositores do Império ainda buscariam nos imigrantes lusos um imaginário ranço monárquico, sem, contudo, deixar de notar a peculiaridade da sua presença na composição populacional da capital brasileira.

Em um quadro contraditório, a condição singular do português no Brasil combinava-se ao antilusitanismo, cuja expressão pós-monarquista constituiu apenas uma faceta daquele grupo imigrante. Em Janeiro de 1897, o governo da República enviou o navio cruzador Benjamin Constant a Trindade, onde fincou um marco de pedra com a inscrição "Brazil", para assinalar a soberania sobre o território. O lugar mais propício ao assentamento humano, o único da ilha que viria a ser habitado, foi denominado Praia dos Portugueses, numa homenagem intrigante promovida pelos republicanos brasileiros.

\section{Bibliografia}

ALVES, Francisco das Neves, "O rompimento diplomático brasileiro-lusitano ao final do século XIX, um estudo de caso.”. In Leite, Renato Lopes (org.), Cultura Epoder. Portugal e Brasil no século XX. Curitiba: Juruá, 2003, pp. 89-104.

CARNEIRO, Maria Luiza Tucci - Preconceito racial em Portugal e Brasil colônia. Os cristãos-novos e o mito da pureza de sangue. $3^{\text {a }}$ ed. São Paulo: Editora Perspectiva, 2005.

CARVAlHO, José Murilo de - Os Bestializados. São Paulo: Companhia das Letras, 1987.

CERVO, Amado Luiz; MAGALHÃES, José Calvet de - Depois das caravelas: as relações entre Portugal e o Brasil 1808-2000. Lisboa: Instituto Camões, 2000. 
COSTA, Sérgio Corrêa - A diplomacia do marechal: intervenção estrangeira na Revolta da Armada. $2^{a}$ ed. Brasília: Editora da UnB, 1979.

GARCIA, Eugênio Vargas - Cronologia das relações internacionais do Brasil. Brasília: Fundação Alexandre de Gusmão e Alfa Omega, 2000.

Instituto Brasileiro de Geografia e Estatística - Anuário estatístico - Séries históricas. Rio de Janeiro, 1951.

MAYALL, James - Nationalism and international society. Cambridge: Mass: Cambridge University Press, 1990.

NASCIMENTO, Álvaro - A ressaca da marujada: recrutamento e disciplina na Armada Imperial. $1^{\mathrm{a}}$ ed. Rio de Janeiro: Arquivo Nacional, 2001.

VALLAUD, Dominique - Dictionnaire historique. Paris: Fayard, 1995. 